\title{
Raffaele Scalamandré, Storia e poesia di Baudelaire
}

\section{Mario Richter}

\section{(2) OpenEdition}

\section{Journals}

Édition électronique

URL : https://journals.openedition.org/studifrancesi/39683

DOI : 10.4000/studifrancesi.39683

ISSN : 2427-5856

Éditeur

Rosenberg \& Sellier

\section{Édition imprimée}

Date de publication : 1 décembre 2004

Pagination : 400

ISSN : 0039-2944

\section{Référence électronique}

Mario Richter, «Raffaele Scalamandré, Storia e poesia di Baudelaire », Studi Francesi [En ligne], 143 (XLVIII | II) | 2004, mis en ligne le 30 novembre 2015, consulté le 19 mai 2021. URL : http:// journals.openedition.org/studifrancesi/39683; DOI : https://doi.org/10.4000/studifrancesi.39683

Ce document a été généré automatiquement le 19 mai 2021.

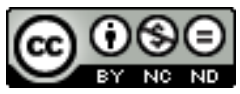

Studi Francesi è distribuita con Licenza Creative Commons Attribuzione - Non commerciale - Non opere derivate 4.0 Internazionale. 


\title{
Raffaele Scalamandré, Storia e poesia di Baudelaire
}

\author{
Mario Richter
}

\section{RÉFÉRENCE}

RAFFAELE SCALAMANDRÉ, Storia e poesia di Baudelaire, Napoli, Edizioni Scientifiche Italiane, 2002. pp. 156.

1 S'adressant en particulier aux lecteurs de son propre pays (toutes les citations en prose y sont en effet données uniquement en traduction italienne), avec ce petit livre Raffaele Scalamandré s'est proposé de donner une vision d'ensemble du «mythe» baudelairien et, en tout premier lieu - comme l'affirme lui-même -, de vérifier en quoi consistent les caractéristiques humaines et spirituelles du poète, sans négliger cependant leur rapport avec la poésie.

2 L'auteur s'attache tout d'abord à reconsidérer la destinée poétique de Baudelaire, dont le soin formel prôné par la théorie de «l'art pour l'art» ne va pas sans un respect profond de l'homme, de ses sentiments et de ses passions. Il cherche ensuite, à travers des poèmes célèbres tels que «Correspondances» et l'«Hymne à la beauté», à préciser la nature de l'esthétique baudelairienne, suspendue entre une aspiration vers Dieu et une attraction vers Satan.

3 Constamment à la recherche des dynamiques complexes dont se constituent les «formes de l'esprit baudelarien», M. Scalamandrè se déclare convaincu de «l'autenticité de la tension spirituelle, religieuse, du poète», tout en reconnaissant que souvent la disponibilité de Baudelaire devant la foi semble être exposée à des déviations, à des soubresauts, à des fluctuations d'humeur, à des arrière-pensées lui interdisant d'atteindre un véritable apaisement intérieur et lui faisant «souvent perdre la mesure des choses et de lui-même». Jugeant ouvertement Baudelaire du point de vue du croyant chrétien, l'auteur s'efforce avec sérieux d'en montrer les «difficultés existentielles» et les limites des différentes expressions simultanées ainsi que des 
nombreuses ambivalences attribuées à la fameuse «double postulation de l'âme». Cela l'amène à revenir sur un sujet particulièrement épineux, celui de la religion de Baudelaire, pour affirmer qu'au poète «ne manquait pas le goût de la foi, bien qu'il ne sût pas quel contenu lui donner», et pour en arriver à la conclusion générale que voici: «Baudelaire avait raison de considérer les hommes - quoique hypocrites - comme des frères. Nous résistons à la séduction de ce genre de fraternité et sommes prêts à le répudier, à le condamner. Mais Baudelaire avait au moins l'avantage, dans la solitude chargée d'une souffrance qu'il rechercha, de connaître effectivement la douleur et donc de pouvoir dire, sans rhétorique, comme elle était faite, sans jamais cesser de regarder la lumière, qui lui apparut pleinement dans la poésie».

4 Tout en respectant le point de vue de l'auteur et la passion sincère, existentielle, qui le guide à tout instant dans la tentative d'expliquer la nature de l'univers baudelairien, nous croyons que ses préoccupations spirituelles finissent par constituer un obstacle insurmontable l'empêchant de pénétrer avec efficacité dans la réalité intime - un véritable inconnu pour notre culture - que Baudelaire voulut et sut explorer, notamment dans Les Fleurs du Mal, le livre que le poète lui-même qualifiait d'«atroce». 